\title{
External Beam Radiotherapy for Focal Lymphoepithelioma-Like Carcinoma in the Urinary Bladder: A Case Report and Literature Review
}

\author{
Nobuhiro Kushida $^{a}$ Takashi Kushakabe $^{b}$ Masao Kataoka $^{a}$ \\ Shin Kumagai ${ }^{a}$ Ken Aikawa ${ }^{a}$ Yoshiyuki Kojima \\ ${ }^{a}$ Department of Urology, Fukushima Medical University School of Medicine, Fukushima, \\ and ${ }^{\mathrm{b}}$ Department of Pathology, Jyusendo General Hospital, Koriyama, Japan
}

\section{Key Words}

Bladder cancer · Lymphoepithelioma-like carcinoma - External beam radiotherapy

\begin{abstract}
Lymphoepithelioma is a malignant epithelial tumor in the nasopharynx characterized by prominent lymphoid infiltration. Carcinomas that resemble lymphoepitheliomas have been called lymphoepithelioma-like carcinomas and have been reported in other organs. A tumor in the bladder is categorized by the percentage of the total area occupied by the lymphoepithelioma-like carcinoma pattern, with the prognosis dependent on the percentage. We present an 81-year-old man with stage 3 chronic obstructive pulmonary disease and a history of aortic aneurysm repair. The computed tomography scans indicated thickening and irregularity of the bladder wall, with left external iliac lymph node metastasis. His diagnosis was bladder cancer, and the clinical stage was evaluated as T3N1M0. Transurethral resection of the bladder tumor was performed, and the pathological specimen showed that the tumor was composed of undifferentiated malignant cells with sheets and nests arranged in a syncytial pattern, as well as an urothelial carcinoma lesion. A prominent lymphoid reaction accompanied the tumor. The pathological diagnosis was focal-type lymphoepithelioma-like carcinoma containing a component of urothelial carcinoma G3>G2. His general condition was such that he could not tolerate radical cystectomy or systemic chemotherapy. External beam radiotherapy (total $60 \mathrm{~Gy}$ ) was given to the bladder, including the lymph node metastatic lesion. No cancer recurrence was detected by regular follow-up computed tomography and cystoscopy. He eventually died of other causes 48 months later. Although treatment for focal lymphoepithelioma-like carcinoma generally requires multifocal therapies, in the present case,
\end{abstract}

KARGER 125/s $\quad \begin{aligned} & \text { Nobuhiro Kushida } \\ & \text { Department of Urology } \\ & \text { Fukushima Medical University School of Medicine } \\ & \text { 1, Hikarigaoka, Fukushima 960-1295 (Japan) } \\ & \text { E-Mail no7744@fmu.ac.jp }\end{aligned}$


Kushida et al.: External Beam Radiotherapy for Focal Lymphoepithelioma-Like Carcinoma in the Urinary Bladder: A Case Report and Literature Review

the bladder became tumor free. We also summarize previously reported lymphoepitheliomalike carcinoma cases treated with radiotherapy.

(C) 2015 S. Karger AG, Basel

\section{Introduction}

Lymphoepithelioma is a term used to describe an undifferentiated malignant epithelial tumor in the nasopharynx that is histologically characterized by the existence of prominent lymphoid infiltration. Carcinomas that histologically resemble lymphoepitheliomas have been called lymphoepithelioma-like carcinomas (LELCs). LELCs developing in other organs, e.g. upper pharynx, salivary glands, thymus gland, skin, and lung, have also been reported. LELCs in the urinary bladder are relatively rare, with about 80 cases reported, and they tend to be in the advanced stage when diagnosed. A focal LELC case that was successfully treated with radiotherapy is reported here.

\section{Case Report}

The patient was an 81-year-old man with asymptomatic macroscopic hematuria. His performance status was grade 1 , and he had no occupational exposure to chemical agents. He had stage 3 chronic obstructive pulmonary disease caused by smoking over 40 years and a history of aortic aneurysm repair. He was diagnosed as having bladder cancer by cystoscopic examination and was referred. Computed tomography (CT) showed thickening and irregularity of the whole bladder, with left external iliac lymph node metastasis (fig. 1). The clinical stage was diagnosed as T3N1M0 based on the UICC classification. To make a pathological diagnosis and reduce the mass of the tumor, transurethral resection of the bladder tumor (TURBT) was performed, and the tumor, including the deep muscle layer, was resected. The inside of the bladder, from the triangular area to the posterior wall, was filled with a tumor, approximately $4.0 \times 4.5 \mathrm{~cm}$, that bled easily. On microscopic examination, the tumor was composed predominantly of undifferentiated malignant cells, with sheets and nests arranged in a syncytial pattern, as well as an urothelial carcinoma lesion. The tumor was also accompanied by a prominent lymphoid reaction consisting of mature lymphoidocytes and plasma cells, which invaded into the muscle layer. On immunohistochemical studies, undifferentiated tumor cells were positively stained by epithelial markers (cytokeratin AE1/AE3, CAM5.2, and cytokeratin 7). The infiltrating lymphocytes were stained by CD3 and CD20 (fig. 2). The pathological diagnosis was focal-type LELC containing a component of urothelial carcinoma G3>G2, infiltrative-type. Urine cytology was found to be positive 1 month after TURBT treatment. His general condition was such that it was felt that he would not be able to tolerate radical cystectomy or systemic chemotherapy because of his advanced age and his history of severe chronic obstructive pulmonary disease and aortic aneurysm repair. Therefore, external beam radiotherapy was selected as a less invasive treatment. A total dose of 60 Gy was irradiated to the bladder, including the area of lymph node metastases. The CT scan 3 months after radiotherapy showed no evidence of disease in the bladder and lymph nodes. Four months after radiotherapy, multi-sectional random biopsies confirmed no cancer cells in specimens from the mucosal to muscle layers. No cancer recurrence was detected on regular follow-up by whole-body CT scans and cystoscopy every 6 months, as well as urine cytology. The patient eventually died of heart failure 48 months later. 
Kushida et al.: External Beam Radiotherapy for Focal Lymphoepithelioma-Like Carcinoma in the Urinary Bladder: A Case Report and Literature Review

\section{Discussion}

Since LELC in the urinary bladder was first reported by Zukerberg et al. [1] in 1991, about 80 cases have been reported. Although lymphoepithelioma in the nasopharynx is caused by Epstein-Barr (EB) virus infection, LELC cases in the bladder are normally considered to have little association with EB virus. EB virus was also not detected in the present case by an in situ hybridization method using EB virus-encoded RNA-EBER1, that is, using small non-coding RNAs localized in the nucleus of human cells infected with EB virus. LELC is composed of diffuse sheets and nests of large undifferentiated malignant epithelial cells intermingled with prominent epithelial cells. Mature lymphocytes, plasma cells, histiocytes, and, rarely, neutrophil and eosinophil leukocytes comprise the lymphoid reaction. The differential diagnosis of LELC in the bladder may be lymphoma or chronic inflammation. The immunohistochemical findings, using epithelial markers or cytokeratins, are invaluable in confirming their epithelial origin $[1,2]$. LELCs in the bladder have been stratified and categorized by Amin et al. [3] based on the percentage of the LELC pattern within the tumor: pure $(100 \%)$, predominant $(>50 \%)$, and focal $(<50 \%)$. The subhistotypes of predominant and focal LELCs were mostly urothelial carcinoma, adenocarcinoma, or squamous cell carcinoma. Over $80 \%$ of LELC cases had invasion within the muscle layer [4]. However, most reported cases of LELC of pure or predominant types had a relatively favorable prognosis, with a disease-specific survival rate of $93 \%$ for both pure and predominant types. On the other hand, the prognosis of focal LELCs was quite poor (almost 0\%) [4]. Compared with the strong invasive ability of LELC, lymph node metastasis is rare and occurs in only $10-20 \%$ of cases.

Because of the small number of reported cases, there are no clear guidelines for the treatment of LELC in the bladder. TURBT resecting deep muscle layers or cystectomy is generally performed as local therapy. Radical cystectomy was selected in 40\% [2] and 35\% [4] of cases reported in the literature. On the basis of the sensitivity to chemotherapy reported in lymphoepithelioma cases in the nasopharynx, LELC in the bladder was also successfully treated with cisplatin-based systemic chemotherapy as adjuvant therapy following TURBT or cystectomy [5]. It has been suggested that pure and predominant LELC is sensitive to chemotherapy and may be best treated with bladder preservation $[2,4,6]$. On the other hand, the more aggressive character of focal LELC in the bladder seems to indicate that the best management suitable for the classification would be multifocal therapies, including radical cystectomy and adjuvant systemic chemotherapy, as for advanced conventional urothelial carcinoma [3, 4].

In the present case, the patient's advanced age and complications led to treatment with TURBT and external beam radiotherapy, including the lymph node metastasis. Although the pathology was focal-type LELC, the second TURBT after 4 months showed no cancer cells, and long-term disease-free status was achieved. Reports of radiotherapy for LELC in the bladder have not been abundant. Porcaro et al. [4] reported that $19 \%$ of cases were treated with radiotherapy. Previous literature regarding the salivary gland [7] showed that a combination of surgical resection and postoperative radiotherapy might be appropriate for the locoregional management of LELC. Table 1 summarizes the published papers on radiotherapy for LELC in the bladder with TURBT or open surgery [1-3, 8-10]. Chemoradiotherapy cases were excluded. A total of 15 cases have been reported, and 11 cases were treated with radiotherapy after TURBT. Four cases died from other causes, reflecting the patients' advanced age. Two focal cases of LELC died of disease, and one mixed (predominant or focal) case had an unknown outcome. Evaluations of the general effects of radiotherapy on LELC were difficult because of the small number of patients and the wide variation of the patients' 
Kushida et al.: External Beam Radiotherapy for Focal Lymphoepithelioma-Like Carcinoma in the Urinary Bladder: A Case Report and Literature Review

backgrounds. It was also not clear whether radiotherapy is appropriate as adjuvant or definitive therapy. Since radiotherapy, especially for pure and predominant LELC cases, seems to be comparatively favorable (table 1), it should be one of the treatment options. In particular, it seems to be suitable for patients who have comorbidities and would be unsuitable for cystectomy or would poorly tolerate systemic chemotherapy. Although the present patient with focal LELC became free of cancer, given the reported poor prognosis, multifocal therapy, including cystectomy, would likely be advantageous for patients with focal LELC. Therefore, radiotherapy for pure and predominant LELC cases involving the bladder after deep layer resection by TURBT seems to be appropriate as a less invasive treatment. As for focal LELC treatments, further accumulation of data is needed.

\section{Conclusions}

Although focal LELC normally requires multifocal therapies, some cases became tumor free with TURBT and radiotherapy. Radiotherapy for pure and predominant LELC cases seems to be a candidate for a less invasive treatment, especially for cases with complications.

\section{Disclosure Statement}

The authors have no conflicts of interest to disclose.

\section{References}

1 Zukerberg LR, Harris NL, Young RH: Carcinomas of the urinary bladder simulating malignant lymphoma. A report of five cases. Am J Surg Pathol 1991;15:569-576.

-2 Tamas EF, Nielsen ME, Schoenberg MP, Epstein JI: Lymphoepithelioma-like carcinoma of the urinary tract: a clinicopathological study of 30 pure and mixed cases. Mod Pathol 2007;20:828-834.

-3 Amin MB, Ro JY, el-Sharkawy T, Lee KM, Troncoso P, Silva EG, Ordonez NG, Ayala AG: Micropapillary variant of transitional cell carcinoma of the urinary bladder. Histologic pattern resembling ovarian papillary serous carcinoma. Am J Surg Pathol 1994;18:1224-1232.

-4 Porcaro AB, Gilioli E, Migliorini F, Antoniolli SZ, Iannucci A, Comunale L: Primary lymphoepithelioma-like carcinoma of the urinary bladder: report of one case with review and update of the literature after a pooled analysis of 43 patients. Int Urol Nephrol 2003;35:99-106.

-5 Mayer EK, Beckley I, Winkler MH: Lymphoepithelioma-like carcinoma of the urinary bladder - diagnostic and clinical implications. Nat Clin Pract Urol 2007;4:167-171.

6 Lopez-Beltran A, Luque RJ, Vicioso L, Anglada F, Requena MJ, Quintero A, Montironi R: Lymphoepitheliomalike carcinoma of the urinary bladder: a clinicopathologic study of 13 cases. Virchows Arch 2001;438:552557.

7 Hsiung CY, Huang CC, Wang CJ, Huang EY, Huang HY: Lymphoepithelioma-like carcinoma of salivary glands: treatment results and failure patterns. Br J Radiol 2006;79:52-55.

$\checkmark 8$ Holmang S, Borghede G, Johansson SL: Bladder carcinoma with lymphoepithelioma-like differentiation: a report of 9 cases. J Urol 1998;159:779-782.

-9 Izquierdo-Garcia FM, Garcia-Diez F, Fernandez I, Perez-Rosado A, Saez A, Suarez-Vilela D, GuerreiroGonzalez R, Beneitez-Alvarez M: Lymphoepithelioma-like carcinoma of the bladder: three cases with clinicopathological and p53 protein expression study. Virchows Arch 2004;444:420-425.

10 Kozyrakis D, Petraki C, Prombonas I, Grigorakis A, Kanellis G, Malovrouvas D: Lymphoepithelioma-like bladder cancer: clinicopathologic study of six cases. Int J Urol 2011;18:731-734. 


\section{Case Reports in Oncology}

\begin{tabular}{l|l}
\hline \multicolumn{2}{l}{ Case Rep Oncol 2015;8:15-20 } \\
\hline DOI: $10.1159 / 000371562$ & $\begin{array}{l}\text { ○ 2015 S. Karger AG, Basel } \\
\text { www.karger.com/cro }\end{array}$ \\
\hline
\end{tabular}

Kushida et al.: External Beam Radiotherapy for Focal Lymphoepithelioma-Like Carcinoma in the Urinary Bladder: A Case Report and Literature Review

Table 1. Summary of published cases of radiotherapy for LELC involving the urinary bladder after TURBT or cystectomy, excluding cases treated with combined radiation and chemotherapy

\begin{tabular}{|c|c|c|c|c|c|c|c|c|c|c|}
\hline No. & $\begin{array}{l}\text { First author } \\
\text { [reference] }\end{array}$ & $\begin{array}{l}\text { Age, } \\
\text { years }\end{array}$ & Sex & Classification & $\begin{array}{l}\text { Sub- } \\
\text { histology }\end{array}$ & Stage & Treatment & $\begin{array}{l}\text { Total dose of } \\
\text { radiation, Gy }\end{array}$ & $\begin{array}{l}\text { Follow-up, } \\
\text { months }\end{array}$ & Outcome \\
\hline 1 & Amin [3] & 67 & $\mathrm{~F}$ & predominant & adeno & $\mathrm{T} 3 \mathrm{~b}$ & $\begin{array}{l}\text { partial cystectomy and } \\
\text { radiation }\end{array}$ & not stated & 36 & NED \\
\hline 2 & Holmang [8] & 61 & $\mathrm{~F}$ & pure & - & $\mathrm{T} 2$ & TURBT and radiation & 70 & 216 & death by other cause \\
\hline 3 & Holmang [8] & 78 & M & pure & - & $\mathrm{T} 1$ & TURBT and radiation & 67 & 13 & death by other cause \\
\hline 4 & Holmang [8] & 71 & $\mathrm{~F}$ & predominant & UC & T3 & TURBT and radiation & 67 & 21 & death by other cause \\
\hline 5 & Holmang [8] & 60 & $\mathrm{~F}$ & predominant & UC & T3 & $\begin{array}{l}\text { preoperative radiotherapy } \\
\text { and cystectomy }\end{array}$ & not stated & 104 & NED \\
\hline 6 & Holmang [8] & 72 & M & focal & UC & Т3 & $\begin{array}{l}\text { preoperative radiotherapy } \\
\text { and cystectomy }\end{array}$ & not stated & 68 & DOD \\
\hline 7 & Holmang [8] & 71 & M & focal & UC & T3 & TURBT and radiation & 62 & 9 & DOD \\
\hline 8 & Izquierdo-Garcia [9] & 74 & M & focal & UC & $\mathrm{T} 1$ & TURBT and radiation & 66 & 54 & NED \\
\hline 9 & Izquierdo-Garcia [9] & 77 & M & pure & - & $\mathrm{T} 2$ & TURBT and radiation & 67 & 39 & NED \\
\hline 10 & Izquierdo-Garcia [9] & 82 & $\mathrm{~F}$ & predominant & not stated & $\mathrm{T} 1$ & TURBT and radiation & not stated & 36 & NED \\
\hline 11 & Kozyrakis [10] & 72 & M & predominant & not stated & $\mathrm{T} 2$ & TURBT and radiation & not stated & 72 & NED \\
\hline 12 & Kozyrakis [10] & 80 & $\mathrm{~F}$ & predominant & not stated & $\mathrm{T} 2$ & TURBT and radiation & not stated & 13 & NED \\
\hline 13 & Tamas [2] & not stated & not stated & pure & - & $\mathrm{T} 4$ & cystectomy and radiation & not stated & 36 & NED \\
\hline 14 & Tamas [2] & not stated & not stated & $\begin{array}{l}\text { predominant } \\
\text { or focal }\end{array}$ & UC & $\mathrm{T} 2$ & TURBT and radiation & not stated & 4 & abdominal spread \\
\hline 15 & Zukerberg [1] & 76 & M & pure & - & not stated & TURBT and radiation & not stated & not stated & not stated \\
\hline 16 & Present case & 82 & M & focal & UC & T3 & TURBT and radiation & 60 & 48 & death by other cause \\
\hline
\end{tabular}

adeno = Adenocarcinoma; $\mathrm{UC}=$ urothelial carcinoma; NED = no evidence of disease; $\mathrm{DOD}=$ death of disease.
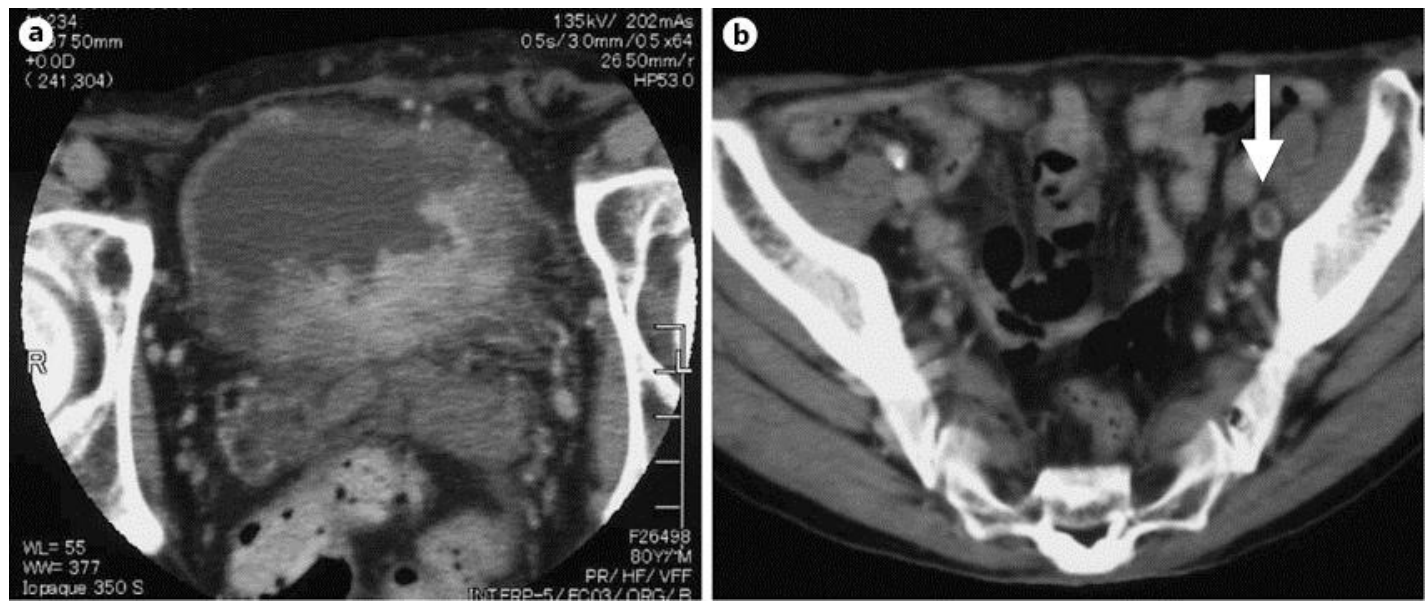

Fig. 1. CT scans. a The tumor has spread into the deep bladder wall layer. $\mathbf{b}$ The arrow indicates external iliac lymph node swelling. 


\section{Case Reports in Oncology}

Case Rep Oncol 2015;8:15-20

Kushida et al.: External Beam Radiotherapy for Focal Lymphoepithelioma-Like Carcinoma in the Urinary Bladder: A Case Report and Literature Review
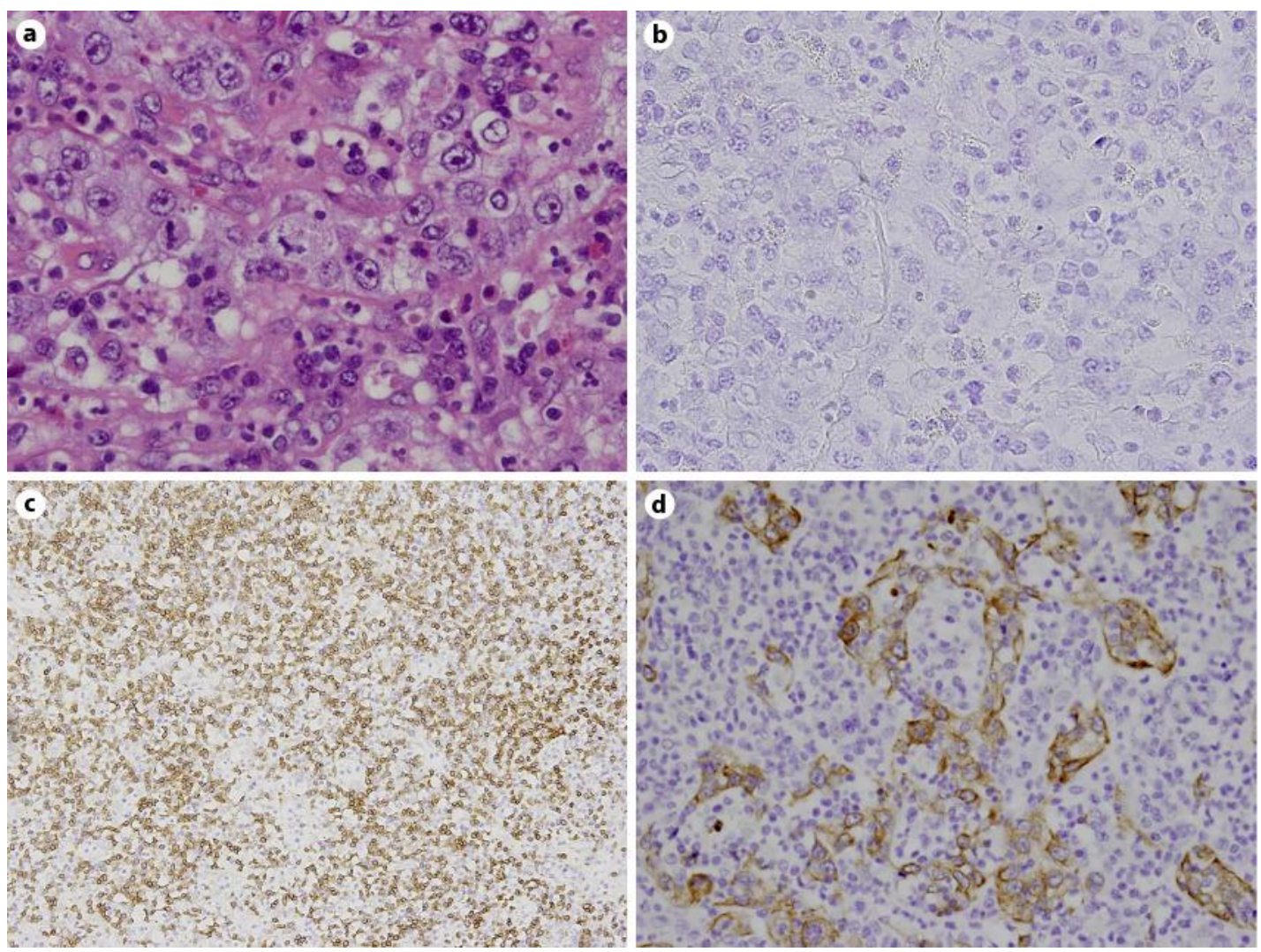

Fig. 2. Pathological findings. a The tumor cells have a clear nuclear body and karyomitosis. They show a syncytial pattern and are surrounded by infiltrated lymphocytes. Hematoxylin-eosin staining. $\times 400$. b The tumor cells and stromal lymphocytes are not stained by EBER1. Immunohistochemical staining. $\times 400$. c The stromal lymphocytes are stained by CD3. Immunohistochemical staining. $\times 100$. $\mathbf{d}$ The tumor cells are stained by cytokeratin AE1/AE3. Immunohistochemical staining. $\times 200$. 